\title{
PSYCHOLOGICAL IMPACT OF ALTERATIONS IN SEXUALITY, FERTILITY, AND BODY IMAGE IN YOUNG BREAST CANCER PATIENTS AND THEIR PARTNERS
}

\author{
Melina Miaja ${ }^{1,2 *}$, Alejandra Platas ${ }^{1}$ and Bertha Alejandra Martinez-Cannon ${ }^{1,2}$ \\ ${ }^{1}$ Joven y Fuerte: Programa para la Atención e Investigación de Mujeres Jóvenes con Cáncer de Mama, Mexico City; \\ ${ }^{2}$ Centro de Cáncer de Mama, Tecnológico de Monterrey, Monterrey, N.L. Mexico
}

\begin{abstract}
Young women with breast cancer have age-specific concerns regarding changes in sexuality, fertility, and body image. However, the psychological impact of $\mathrm{BC}$ and its treatments is not exclusive to young patients and it also affects their social context, especially their partners, as they experience higher illness intrusiveness than the partners of older women. In young BC patients, relationships, body image, and sexual problems are related to most quality of life domains. While BC treatment is being planned, all women should be informed about the possible side-effects of treatment on sexuality, fertility, and body image. Inclusion of partners into decision making should be pursued to restore, improve, and maintain effective communication and positive relationships in young couples facing BC. The aim of this review is to describe the psychological impact of alterations in sexuality, fertility, and body image in young $\mathrm{BC}$ patients and their partners, and to recommend strategies to address such issues in a timely manner.
\end{abstract}

Key words: Psychological impact. Sexuality. Fertility. Body image. Young breast cancer. Partners.

\section{INTRODUCTION}

Breast cancer $(B C)$ is the most frequent malignancy in women and the leading cause of cancer death in women in developing countries ${ }^{1}$. The diagnosis and treatment of BC affect physical, psychological, and social aspects of everyday life. These impacts occur at diagnosis, during treatment, and along survivorship ${ }^{2-4}$. Being diagnosed with a life-threatening disease, such as $B C$, interferes with life plans and results on the perception of cancer as a highly disruptive illness ${ }^{5}$. It has been suggested that women with $B C$ experience it differently depending on their age at diagnosis ${ }^{6,7}$.

Young women (40-year-old or younger at diagnosis) have specific concerns regarding professional careers,

\section{Corresponding author:}

*Melina Miaja

Batallón San Patricio, 112

Real de San Agustín

C.P. 66278 , San Pedro Garza García, N.L., México

E-mail: miajaam@live.com.mx family roles, childcare issues, relationships, body image changes, marital strains, and alienation from healthy peers ${ }^{8}$. Furthermore, they tend to perceive cancer as more aggressive and disruptive than their older counterparts ${ }^{9,10}$. In addition, BC diagnosis is more challenging in young women than it is usually assumed to be in older women, and is associated with worse clinical outcomes ${ }^{11}$.

Avis et al. reported that loss of daily routine, sexual problems, and dissatisfaction with body image are important factors that affect negatively the quality of life of women under 50 years ${ }^{12}$. Champion et al. found similar results when comparing young survivors of $\mathrm{BC}$ with older survivors, as young women presented greater depression and anxiety symptoms in response
Received for publication: 17-05-2017

Approved for publication: 12-06-2017

doi: $10.24875 /$ RIC.17002279 
to stressful life events, increased fatigue and fear of recurrence, as well as lower performance in social support, marital satisfaction, perceived benefit of cancer experience, spirituality, levels of attention, perception of body image, and sexual functioning ${ }^{7}$. In addition, young $B C$ patients experience important changes in their interpersonal relationships and often have to make significant adjustments in their daily lives to care, support, and protect their loved ones ${ }^{13}$.

The psychological impact of $B C$ is not exclusive to young patients and it also affects their social context, especially their partners ${ }^{13-16}$. Partners of young women compared with partners of older women with BC experience higher illness intrusiveness, maladaptive dyadic coping, worse psychological distress, and greater difficulty in communicating their cancer-related concerns, including recurrence and fear of losing their partners ${ }^{14,15}$. Furthermore, Gotay found that the partners of young women were more concerned about the possibility of death than the patients themselves ${ }^{16}$.

Current guidelines for $\mathrm{BC}$ recommend surgery, radiation therapy, chemotherapy, and/or hormonal therapy in young women ${ }^{17}$. Although cancer treatment has been shown to improve clinical outcomes ${ }^{18}$, it confers serious side effects with possible impact on sexual function, fertility, and body image. Psychological support for these age-specific concerns has been identified as essential in the comprehensive care of young $\mathrm{BC}$ patients and their partners. Therefore, these aspects should be systematically addressed in every young BC patient ${ }^{2,3,19-23}$.

The aim of this review is to describe the psychological impact of alterations in sexuality, fertility, and body image in young BC patients and their partners, and to recommend strategies to opportunely address these issues.

\section{SEXUALITY}

Various BC treatment modalities, including chemotherapy, endocrine therapy, and ovarian ablation, often affect the emotional state, quality of life and sexual function of patients ${ }^{24}$. Sexual dysfunction is highly prevalent among young women with breast cancer (YWBC). In a study of YWBC in the Netherlands, a sexual dysfunction was reported by $64 \%$ of patients who were still undergoing treatment and $45 \%$ of patients who had completed treatment ${ }^{19}$. In spite of this high prevalence, during medical appointments, only a small number of patients and healthcare professionals bring up the effects of treatment on sexuality and intimacy ${ }^{25}$. Sexual dysfunction in YWBC is characterized by vaginal dryness, dyspareunia, amenorrhea, loss of sexual desire, decreased frequency of sexual activity, difficulty reaching orgasm, and anxiety about sexual performance ${ }^{26,27}$.

Champion et al. found that nearly half of young women reported a decrease in the following domains of sexual function: Sexual interest (48\%), arousal (44\%), lubrication ( $52 \%)$, orgasm ( $38 \%)$, frequency ( $41 \%)$, ability to relax ( $41 \%$ ), and fantasies ( $41 \%$ ). In addition, $41 \%$ of young women indicated that their sexual relations had worsened and $40 \%$ that their sexual enjoyment had diminished ${ }^{7}$.

Sexual difficulties are present during treatment and continue through the follow-up period in the majority of patients ${ }^{19,28-30}$. However, concerns about sexuality seem to be more frequent at the beginning of treatment, specifically during chemotherapy and trastuzumab therapy, than during hormone therapy and follow-up ${ }^{30}$. A qualitative study showed that regardless of the stage of treatment, YWBC reported more sexual problems than their partners ${ }^{30}$. Furthermore, partners of young survivors present more depression and worse sexual functioning indicated by lower enjoyment, more sexual difficulty, lower marital satisfaction, and lower overall well-being compared to partners of age-matched controls without $\mathrm{BC}^{29}$.

Several predictors of sexual dysfunction have been identified in young women, including physical and psychosocial factors. Ganz et al. found that vaginal atrophy, dryness, and dyspareunia increase the risk of sexual dysfunction ${ }^{31}$. Lee et al. identified that chemotherapy-induced thyroid dysfunction and depression are independent risk factors for sexual inactivity ${ }^{32}$. Rosenberg et al. reported that vaginal pain symptoms, poor body image, and fatigue were independently associated with sexual dysfunction. Altered body image, mastectomy, and weight gain were also found to have a negative influence on the patients' sexual function ${ }^{33,34}$.

There are some components that could enhance the communication and coping of BC patients and their partners toward sexual changes. Specialists recommend that patients and partners have a sense of structure, safety and support to face the sexual changes their relationship may suffer during and after BC treatment. In partnered patients, the quality of their relationship is 
a critical and concordant predictor of sexual functioning, surpassing physical changes as a determinant for sexual health. The partner's understanding and acceptance, a strong intimate bond, good communication, and affection, all help in the sexual renegotiation process that follows the oncologic experience ${ }^{35}$.

For patients without a partner, it is important to emphasize that sexuality is not exclusive to couples, and that they can also maintain a healthy sexual life. The following are recommendations to improve sexual function in $\mathrm{BC}$ patients and their partners:

1. Promote the use of vaginal moisturizer 2 or more times a week, in case of vaginal thinning and dryness

2. Motivate patients to share their concerns about sexuality

3. Motivate patients to talk about their diagnosis and its treatment, in case they have a new partner

4. Create a greater sense of closeness between partners through the promotion of intimacy, relationship awareness, constructive listening and communication skills

5. Promote sharing the meaning of cancer in the relationship and identifying overall positive effects on the relationship

6. Create opportunities for partners to reflect on and communicate about individual and shared strengths and to identify and share thoughts and feelings toward BC

7. Promote effective communication, to increase the understanding of the other person's perspective.

\section{FERTILITY}

BC treatment may cause premature ovarian failure; therefore, discussing the risk of infertility is a critical issue in newly diagnosed young $B C$ patients ${ }^{36}$. Due to the current trend to defer childbearing to later in life, concerns regarding fertility and future pregnancies are unique to the younger population of patients with $B C$, as some may not have started or completed their family plans at the time of diagnosis ${ }^{37}$.
Communication about fertility preservation options and appropriate referral to a specialist are both critical to quality of life of young BC patients and may also impact disease outcomes ${ }^{38}$. Women who received a cancer diagnosis have indicated that the feeling of distress associated with the threat to fertility posed by cancer treatment was on par with the distress associated with BC diagnosis ${ }^{39}$. Patients with no fertility preservation counseling before the initiation of therapy and patients who rendered infertile posttreatment have expressed considerable anxiety and remorse over the lack of information and timely referral ${ }^{40}$.

Few women receive information on the risk of fertility loss and even less pursue assisted reproductive techniques before chemotherapy ${ }^{20,21}$. The implementation of oncofertility programs has shown that patients value fertility in the context of their cancer treatment and that they do not voice these concerns unless they are prompted to do $\mathrm{so}^{38}$. After the establishment of this kind of programs, the number of patients who express their interest in fertility preservation has risen ${ }^{38}$. Moreover, existing programs with a patient-centered approach have shown to improve unmet needs reported by patients, but not their partners ${ }^{41,42}$.

In a study conducted in two Mexican referral centers, only $30.6 \%$ of patients recalled having received from their physician's information regarding infertility risk ${ }^{43}$. In a study on focus groups conducted by our group, young patients were concerned over the possibility of not being able to be mothers in the future. Furthermore, they felt annoyed by not receiving information on the possible effects of chemotherapy on ovarian function before treatment initiation, not being referred to fertility specialists in a timely manner, and the short-time they had to take decisions on fertility preservation and cancer treatment. Another concern expressed was the possibility of getting pregnant at an older age and the fear of developing cancer again, leaving a maternal figure to the children they wish they had (unpublished data).

Decision-making about fertility preservation is complex, with many ill-defined risk factors. Educational materials should be available to increase knowledge and assist decision-making; furthermore, providers should address individual values and preferences to reduce decisional conflict without increasing anxiety. Peate et al. found that most young women preferred an active role in decision-making but also wished to take into account 
medical advice, and those who preferred a passive role still wished for their opinions and personal values to be considered before the physician made the decision ${ }^{44}$.

Decision-making about fertility preservation and cancer treatment is influenced by diverse factors such as perceived benefits, costs, and the influence of value relationships ${ }^{45}$. While young women saw themselves as the primary decision-maker, partnered patients often considered their partners' parenting desires and turned to them to support their decision. In the absence of a partner, most women sought their parents' advice and, at times, were even pressed by their parents into undergoing fertility preservation strategies, pursuing their own desire for grandchildren ${ }^{45}$.

The following actions should be considered to achieve integral care and to reduce psychological side effects caused by the potential consequences of oncological treatment on fertility in young $B C$ patients:

1. Explore accurately the fertility-related needs of all BC patients 40 years or younger

2. Determine a standardized narrative for providers to introduce routinely the fertility side effects and options for preservation when discussing oncologic treatment with newly diagnosed patients

3. Provide comprehensive information about fertility options

4. Facilitate timely and personalized counseling for decision making. Women must be assessed to confirm they have the adequate knowledge to make informed decisions. In case they have partners, they should be actively involved in the decision-making process

5. Help patients as they pursue assisted reproduction techniques and provide resources, including a fertility specialist to answer their questions.

\section{BODY IMAGE}

Raich defines the body image as a complex construct that includes the body's perception as a whole and its individual parts, as well as its movement and limitations ${ }^{46}$. For women, the body image includes feeling feminine and attractive ${ }^{47}$; therefore, the meaning of the physical alteration due to $B C$ represents one of the factors that most influence the adaptation and assimilation of a new body image ${ }^{48}$. In addition, a poor body image in YWBC has been associated to greater physical and psychological distress ${ }^{49}$ and is often overlooked by health professionals ${ }^{22}$.

The most frequently reported losses by BC patients are corporal as these are real and visible to others. For YWBC, body image is altered by the loss of their breast(s), hair, or physical functions, the presence of surgical scars, weight changes and lymphedema, which can potentially impair the overall quality of life $\mathrm{e}^{50-52}$.

Few studies have explored prospectively the impact of BC in body image in young women. Rosenberg et al. found that oncologic treatment, including radical surgery and radiation, and physical and psychological symptoms were factors associated with more body image concerns in young women ${ }^{52}$. Patients who underwent a surgical procedure usually feel deformed, mutilated, asymmetrical, less feminine and sexually attractive, have a diminished personal value and tend to avoid looking at themselves naked ${ }^{26,50,51,53}$. Kurowecki and Fergus showed that for young patients, BC meant an assault on a women's sense of self-esteem, creating new insecurities and exacerbating old, and irrevocably changing the identity of women ${ }^{54}$. A qualitative study on women undergoing breast reconstruction found that those who had inaccurate expectations experienced higher levels of dissatisfaction with the surgical results ${ }^{55}$.

Attacks on body image, low self-esteem and feelings of sadness or stress are frequently present during and after cancer treatment in YWBC. The following are recommendations to soften the impact of these changes and to promote the acceptance of a new body image:

1. Exercise on self-esteem of young BC patients

2. Promote weight training and physical activity during treatment to improve body image and other psychosocial outcomes

3. Help manage symptoms and improve their body image through psycho-educational interventions

4. Inform women of the potential image concerns associated with radical surgery

5. Promote real expectations through education and counseling before surgery to improve satisfaction 
6. Provide special makeup techniques to help women feel more like themselves.

\section{CONCLUSIONS}

In young $\mathrm{BC}$ patients, relationships, body image, and sexual problems are related to most quality of life domains. While BC treatment is being planned, all women should be informed about the possible side-effects of treatment on sexuality, fertility, and body image. Inclusion of partners into decision-making should be pursued to restore, improve, and maintain effective communication and positive relationships in young couples facing $B C$. Despite that the psychological impact of BC on sexuality, fertility, and body image in young women and their partners has been identified, these critical issues are not systematically addressed in the comprehensive care to these patients. Existing programs with a patient-centered approach have been shown to improve unmet needs reported by patients, but not their partners. Further research is needed on identifying factors associated with poor body image, fertility issues, and sexual dysfunction in partners of YWBC. Couple-based psychosocial interventions for women and their partners may favor a better adjustment during the disease process and the changes it entails.

\section{REFERENCES}

1. World Health Organization (WHO). Breast Cancer. Estimated Incidence, Mortality and Prevalence Worldwide in 2012; 2014. p. 22-4. Available from: http://www.globocan.iarc.fr/Pages/ fact_sheets_cancer.aspx.

2. Adams E, McCann L, Armes J, Richardson A, Stark D, Watson E, et al. The experiences, needs and concerns of younger women with breast cancer: A meta-ethnography. Psychooncology. 2011;20:851-61.

3. Howard-Anderson J, Ganz PA, Bower JE, Stanton AL. Quality of life, fertility concerns, and behavioral health outcomes in younger breast cancer survivors: A systematic review. J Natl Cancer Inst. 2012;104:386-405.

4. Fernandes-Taylor S, Adesoye T, Bloom JR. Managing psychosocial issues faced by young women with breast cancer at the time of diagnosis and during active treatment. Curr Opin Support Palliat Care. 2015;9:279-84

5. Kangas M, Henry JL, Bryant RA. Predictors of posttraumatic stress disorder following cancer. Health Psychol. 2005;24:579-85.

6. Campbell-Enns HJ, Woodgate RL. The psychosocial experiences of women with breast cancer across the lifespan: A systematic review. JBI Database System Rev Implement Rep. 2015; 13:112-21.

7. Champion VL, Wagner LI, Monahan PO, Daggy J, Smith L, Cohee $A$, et al. Comparison of younger and older breast cancer survivors and age-matched controls on specific and overall quality of life domains. Cancer. 2014;120:2237-46.

8. Ali A, Warner E. Pynk: Breast cancer program for young women. Curr Oncol. 2013;20:e34-9.

9. Bellizzi KM, Blank TO. Predicting posttraumatic growth in breast cancer survivors. Health Psychol. 2006;25:47-56.
10. Bloom JR, Stewart SL, Johnston M, Banks P, Fobair P. Sources of support and the physical and mental well-being of young women with breast cancer. Soc Sci Med. 2001;53:1513-24.

11. Ochoa C, Castejón V, Sumalla EC, Blanco I. Posttraumatic growth in cancer survivors and their significant others : Vicarious or secondary growth ? Ter Psicol. 2013;31:81-92.

12. Avis NE, Crawford S, Manuel J. Quality of life among younger women with breast cancer. J Clin Oncol. 2005;23:3322-30.

13. Christophe V, Duprez C, Congard A, Fournier E, Lesur A, Antoine P, et al. Evaluate the subjective experience of the disease and its treatment in the partners of young women with non-metastatic breast cancer. Eur J Cancer Care. 2016;25:734-43.

14. Acquati C. A Comparison of Younger and Older Couples Coping with Breast Cancer: Examining the Relationship among Mutuality, Dyadic Coping, and Quality of Life of Patients and Partners. Electron Theses Dissertations Paper No. 2392;2016. Available from: http://ir.library.louisville.edu/etd/2392.

15. Baucom DH, Porter LS, Kirby JS, Gremore TM, Keefe FJ. Psychosocial issues confronting young women with breast cancer. Breast Dis. 2006;23:103-13.

16. Gotay CC. The experience of cancer during early and advanced stages: The views of patients and their mates. Soc Sci Med. 1984;18:605-13.

17. Paluch-Shimon S, Pagani O, Partridge AH, Bar-Meir E, Fallowfield L, Fenlon $D$, et al. Second international consensus guidelines for breast cancer in young women (BCY2). Breast. 2016; 26:87-99.

18. Kroman N, Jensen MB, Wohlfahrt J, Mouridsen HT, Andersen PK, Melbye $M$. Factors influencing the effect of age on prognosis in breast cancer: Population based study. BMJ. 2000;320:474-8.

19. Kedde H, van de Wiel HB, Weijmar Schultz WC, Wijsen C. Sexual dysfunction in young women with breast cancer. Support Care Cancer. 2013;21:271-80.

20. Corney RH, Swinglehurst AJ. Young childless women with breast cancer in the UK: A qualitative study of their fertility-related experiences, options, and the information given by health professionals. Psychooncology. 2014;23:20-6.

21. Gonçalves V, Tarrier N, Quinn G. Thinking about white bears: Fertility issues in young breast cancer survivors. Patient Educ Couns. 2015;98:125-6.

22. Ahmad S, Fergus K, McCarthy M. Psychosocial issues experienced by young women with breast cancer: The minority group with the majority of need. Curr Opin Support Palliat Care. 2015;9:271-8.

23. Male DA, Fergus KD, Cullen K. Sexual identity after breast cancer: Sexuality, body image, and relationship repercussions. Curr Opin Support Palliat Care. 2016;10:66-74.

24. Park JH, Bae SH, Jung YM. Changes of symptom distress and quality of life in breast cancer patients receiving adjuvant therapy. Asian Oncol Nurs. 2015;15:67-74.

25. Henson HK. Breast cancer and sexuality. Sex Disabil. 2002:20:261-75

26. Krychman ML, Katz A. Breast cancer and sexuality: Multi-modal treatment options. J Sex Med. 2012;9:5-13.

27. Ebrahimi M, Haghighat S, Mehrdad N, Olfatbakhsh A, Azin A. Sexual dysfunction in breast cancer: A case-control study. Arch Breast Cancer. 2015;2:15-20.

28. Fobair P, Stewart SL, Chang S, D'Onofrio C, Banks PJ, Bloom JR. Body image and sexual problems in young women with breast cancer. Psychooncology. 2006;15:579-94.

29. Champion V, Cohee AA, Monahan P, Stump TE, Miller K, Wagner L, et al. Quality of life difficulties in partners of young breast cancer survivors. J Clin Oncol. 2016;34:188.

30. Vanlemmens L, Duprez C, Lesur A, Kaci FA, Congard A, Antoine P, et al. Concerns about sexuality of young women with breast cancer and their partners. Ann Oncol. 2014;25:481-5.

31. Ganz PA, Greendale GA, Petersen L, Kahn B, Bower JE. Breast cancer in younger women: Reproductive and late health effects of treatment. J Clin Oncol. 2003;21:4184-93.

32. Lee $\mathrm{M}, \mathrm{Kim} \mathrm{YH}$, Jeon MJ. Risk factors for negative impacts on sexual activity and function in younger breast cancer survivors. Psychooncology. 2015;24:1097-103. 
33. Rosenberg SM, Tamimi RM, Gelber S, Ruddy KJ, Bober SL, Kereakoglow $S$, et al. Treatment-related amenorrhea and sexual functioning in young breast cancer survivors. Cancer. 2014;120:2264-71.

34. Raggio GA, Butryn ML, Arigo D, Mikorski R, Palmer SC. Prevalence and correlates of sexual morbidity in long-term breast cancer survivors. Psychol Health. 2014;29:632-50.

35. Pinto AC. Sexuality and breast cancer: Prime time for young patients. J Thorac Dis. 2013;5 Suppl 1:S81-6.

36. Partridge AH, Gelber S, Peppercorn J, Sampson E, Knudsen K, Laufer $M$, et al. Web-based survey of fertility issues in young women with breast cancer. J Clin Oncol. 2004;22:4174-83.

37. Schover LR. Sexuality and fertility after cancer. Hematology Am Soc Hematol Educ Program. 2005:523-7.

38. Vu JV, Llarena NC, Estevez SL, Moravek MB, Jeruss JS. Oncofertility program implementation increases access to fertility preservation options and assisted reproductive procedures for breast cancer patients. J Surg Oncol. 2017;115:116-21.

39. Deshpande NA, Braun IM, Meyer FL. Impact of fertility preservation counseling and treatment on psychological outcomes among women with cancer: A systematic review. Cancer. 2015; 121:3938-47.

40. Jeruss JS. Discussing fertility preservation with breast cancer patients. Cancer Treat Res. 2010;156:461-6.

41. Duggleby W, Bally J, Cooper D, Doell H, Thomas R. Engaging hope: The experiences of male spouses of women with breast cancer. Oncol Nurs Forum. 2012;39:400-6.

42. Kauffmann R, Bitz C, Clark K, Loscalzo M, Kruper L, Vito C. Addressing psychosocial needs of partners of breast cancer patients: A pilot program using social workers to improve communication and psychosocial support. Support Care Cancer. 2016;24:61-5.

43. Villarreal-Garza C, Martinez-Cannon BA, Platas A, Mohar A, Partridge AH, Gil-Moran A, et al. Fertility concerns among breast cancer patients in Mexico. Breast. 2017;33:71-5.

44. Peate M, Meiser B, Friedlander M, Zorbas H, Rovelli S, SansomDaly $U$, et al. It's now or never: Fertility-related knowledge, decision-making preferences, and treatment intentions in young women with breast cancer - An Australian fertility decision aid collaborative group study. J Clin Oncol. 2011;29:1670-7.

45. Snyder KA, Tate AL. What to do now? How women with breast cancer make fertility preservation decisions. J Fam Plann Reprod Health Care. 2013;39:172-8.

46. Raich RM, Quées la imagen corporal? In: Imagen Corporal: Conocer y Valorar el Propio Cuerpo. Madrid: Pirámide; 2000. p. 17-26.

47. Mock V. Body image in women treated for breast cancer. Nurs Res. 1993:42:153-7.

48. Hernández A, Almonacid V, Garcés V. Cáncer e imagen: el duelo corporal. En: Duelo en Oncología. España: Sociedad Española de Oncología Médica, 2014. p. 183-96.

49. Paterson CL, Lengacher CA, Donovan KA, Kip KE, Tofthagen CS. Body image in younger breast cancer survivors: A systematic review. Cancer Nurs. 2016;39:E39-58.

50. Aguilar Cordero MJ, Mur Villar N, Neri Sánchez M, PimentelRamírez ML, García-Rillo A, Gómez Valverde E. Breast cancer and body image as a prognostic factor of depression: A case study in México city. Nutr Hosp. 2014;31:371-9.

51. Aguilar Cordero MJ, Neri Sánchez M, Mur Villar N, Gomez Valverde E, Lopez Sanchez AM. Perception of body image after breast cáncer surgery in women from the city of granada. Rev Española Nutr Comunitaria. 2014;20:2-6.

52. Rosenberg SM, Tamimi RM, Gelber S, Ruddy KJ, Kereakoglow S, Borges VF, et al. Body image in recently diagnosed young women with early breast cancer. Psychooncology. 2013;22: 1849-55.

53. Begovic-Juhant A, Chmielewski A, Iwuagwu S, Chapman LA. Impact of body image on depression and quality of life among women with breast cancer. J Psychosoc Oncol. 2012;30: 446-60.

54. Kurowecki D, Fergus KD. Wearing my heart on my chest: Dating, new relationships, and the reconfiguration of self-esteem after breast cancer. Psychooncology. 2014;23:52-64.

55. Ruddy KJ, Greaney ML, Sprunck-Harrild K, Meyer ME, Emmons KM, Partridge AH. A qualitative exploration of supports and unmet needs of diverse young women with breast cancer. J Community Support Oncol. 2015;13:323-9. 